\title{
Correction to: Perioperative coronary artery spasms in patients undergoing catheter ablation of atrial fibrillation
}

\author{
Masato Hachisuka ${ }^{1} \cdot$ Yuhi Fujimoto $^{1}$ (1) $\cdot$ Eiichiro Oka $^{1} \cdot$ Hiroshi Hayashi $^{1} \cdot$ Teppei Yamamoto $^{1} \cdot$ Hiroshige Murata $^{1} \cdot$ \\ Kenji Yodogawa ${ }^{1} \cdot$ Yu-ki Iwasaki ${ }^{1}$ Meiso Hayashi ${ }^{1,2} \cdot$ Yasushi Miyauchi ${ }^{1} \cdot$ Wataru Shimizu ${ }^{1}$
}

Published online: 24 February 2022

(c) The Author(s) 2022

\section{Correction to: Journal of Interventional Cardiac Electrophysiology https://doi.org/10.1007/s10840-021-01089-6}

In this article a scale has been added to the right side of the precordial leads in Figure 1A, and it just covers the ECG.; the figure should have appeared as shown below.

The original article has been corrected.

A
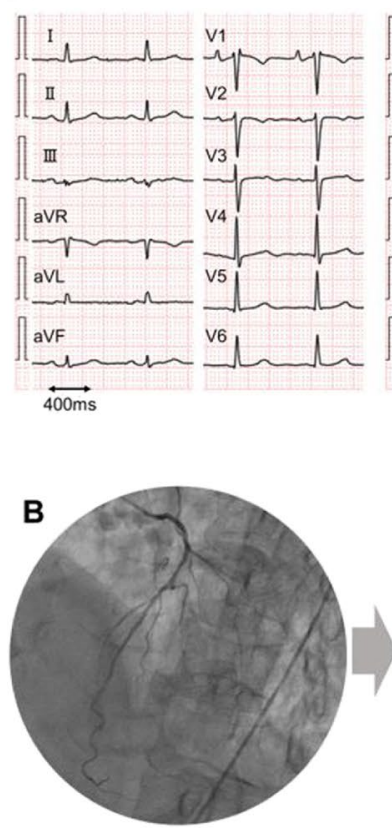
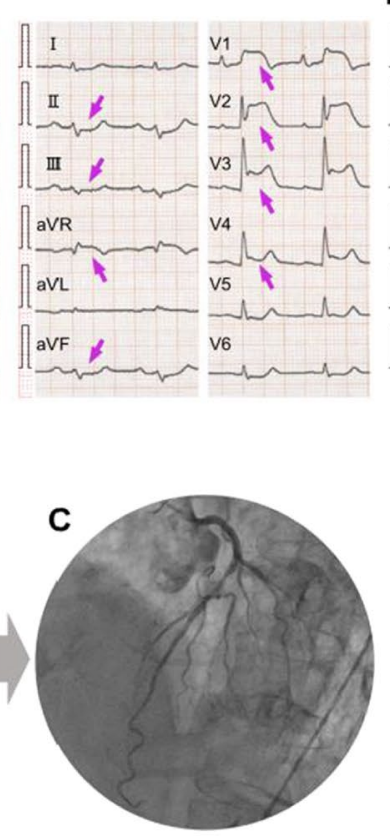

D
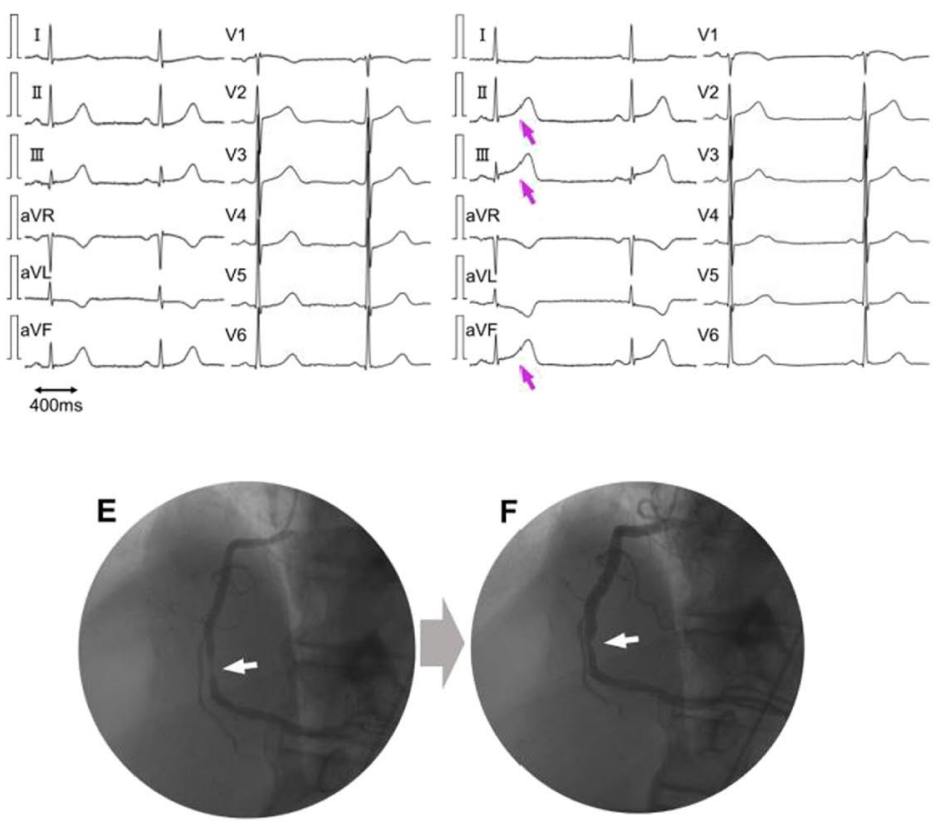

The original article can be found online at https://doi.org/10.1007/ s10840-021-01089-6.

Yuhi Fujimoto

y-fujimoto6081@nms.ac.jp

1 Department of Cardiovascular Medicine, Nippon Medical School, 1-1-5 Sendagi, Bunkyo-ku, Tokyo 113-8603, Japan

2 Mabori Medical Clinic, Yokosuka, Japan 
Open Access This article is licensed under a Creative Commons Attribution 4.0 International License, which permits use, sharing, adaptation, distribution and reproduction in any medium or format, as long as you give appropriate credit to the original author(s) and the source, provide a link to the Creative Commons licence, and indicate if changes were made. The images or other third party material in this article are included in the article's Creative Commons licence, unless indicated otherwise in a credit line to the material. If material is not included in the article's Creative Commons licence and your intended use is not permitted by statutory regulation or exceeds the permitted use, you will need to obtain permission directly from the copyright holder. To view a copy of this licence, visit http://creativecommons.org/licenses/by/4.0/.

Publisher's note Springer Nature remains neutral with regard to jurisdictional claims in published maps and institutional affiliations. 